TẠP CHÍ KHOA HỌC ĐẠI HỌC TÂN TRÀO

ISSN: $2354-1431$

http://tckh.daihoctantrao.edu.vn/

\title{
A study on using corrective feedbacks in teaching essays at school of foreign languages, Thai Nguyen university
}

\author{
Le Thi Nhung ${ }^{a}$, La Thi Thuy Dung ${ }^{a^{*}}$ \\ ${ }^{a}$ Thai Nguyen University \\ *Email:lathuydung.sfl@tnu.edu.vn
}

\section{Article info}

Recieved:

15/7/2018

Accepted:

$10 / 9 / 2018$

Keywords:

SLA, teaching writing, written corrective feedback.

\begin{abstract}
The ability of writing is considered as a main communication skill and "a unique asset" in SLA (Chastain, 1998) that language learners should be fully aware of. Methodology in teaching writing therefore has experienced considerable changes in the approach to teaching and assessing learners. Written corrective feedback as a response channel to students' writings in SLA classrooms has been a topic of inclusive debates and inquiries amongst the scholarly sphere. Contributing to this bulk of controversy, the present study investigates teachers' perceptions and their students' attitudes and evaluations as to the practice of error corrective feedback. To collect data, two different questionnaires of suitable reliability were delivered to sample respondents of 12 teachers and 34 students respectively to elicit data catering the study's purposes. Findings were also triangulated with 5 participant teachers invited for follow-up interviews and a comparative reference to previous studies on written corrective feedbacks. The results revealed that there are no dramatic differences in teachers' attitudes towards the usefulness of written corrective feedbacks. However, when it comes to types and amount of errors they should comment on, teachers' responses and preference cover a wide spectrum.
\end{abstract}

\section{Introduction}

Writing is coined as "the development of an idea, the capture of mental representations of knowledge, and experience with subjects."(Pasand \& Haghi, 2013). It is commonly acknowledged that good writing performance is academically important for learners to master for their communication or study purposes. Therefore, linguists, language teachers and researchers have been interested in strategies to teach and assess students in terms of writing skills. As far as assessment of students' writing is concerned, corrective feedback is a conventionally method applied by teachers. Nevertheless, the correction of students' errors is a topic of controversial and inconclusive issue that has not yet come to a final decision. Groups of scholars and language practitioners seem divided into two ends of the continua - pro-correction and non-correction- as to whether or not the provision of corrective feedback is of significance on attaining fluency and accuracy in writing (Guenette, 2007).

Before 1960, scholars voted for the utter abolition of errors, then in late 1970, they strongly disapproved error correction as this is noxious and unjustified. In his essay titled "The Case against Grammar Correction in L2 Writing Class", John Truscott (1999) argued that on a basis of empirical research, SLA theory and practical concerns, WCF is both 
"ineffective" and "harmful", hence "should be abandoned". The last movement of the debate was in 1980 when the correction of errors was given importance and appreciation (Lee, 2011). Zamel (1983, as cited in Naidu, 2007) claimed that "by studying what learners do in their writings, teachers can learn what learners still need to be taught." According to Muncie (2000) and Myers (1997), this process is supposed to bring effectiveness in enhancing the learners' writing proficiency.

Meanwhile, there is growing evidence that ESL students are craving for error correction and that correction from teachers is effective (Oladejo, 1993; Zhu, 2001; Agudo, 2012). The review of literature shows that the feebleness of error correction is still substantiated as the final aim is a flawless performance will be done by student writers.

\section{Literature Review}

\subsection{Teaching writing and writing goals}

Writing goals vary greatly, depending on the language itself, on communication, and on both forms and messages. In other words, the writers and readers must bear in mind different goals the creation of meaning, the use of language, and the correctness of grammar. In the long-term, writing goals are coined by Elahe Ebadi (2014) as user's ability to use the learned materials to communicate an understandable message to native speakers. Also, when they move up the ladder of study and practice, the requirements of accuracy are raised. To facilitate learners to reach these long goals, teachers need provide and apply different methods of assessment.

\subsection{Error correction}

How competent speakers react to learners' language errors takes on many guises depending on field of researchers (Lyster, 1997). It has been investigated as negative evidence by linguists, repair by discourse analysts, or negative feedback by psychologists, and corrective feedback by language teachers and as focus-on-form in SLA. These different coinages reflect a variety of research concerns and approaches to the collection of data (Schachter, 1991).

\subsection{Written corrective feedback}

\subsubsection{Definition of written corrective feedback}

Investigations into the effect of WCF on student writers cover a broad spectrum of opinions and have inconclusive results. As regard the use of grammar correction, the first group of studies by Kepner, 1991; Sheppard, 1992, Truscott, 2007 believed that grammar correction, as an element in WCF, have no positive impact on bettering L2 writing competency. Furthermore, WCF is even proved to be not only ineffective but also potentially jeopardizing/detrimental (Krashen, 1982 and Truscott, 2007.) Strongly refusing written feedback, Truscott (1999) ascertained that error correction affect negatively student writers' fluency. At the opposite end of the spectrum are Ferris, 2002; Chandler, 2003; Sheen, 2007; and Bitchener and Knoch, 2008 who voiced that $\mathrm{CF}$ is useful as it helps improve grammatical accuracy. Kepner, 1991; Chandler; Hyland, 2003; and Bitchener, 2008 believed that there need more time to conclude the real effectiveness of error correction and that teachers henceforth cannot ignore students' needs of error feedback. As shown by Hyland, 2003; Chandler, 2003, students given error feedback by teachers improve in accuracy as well as fluency over time.

As far as the effects of focused and unfocused feedback is concerned, Ellis, Sheen and Murakami in 2008 agreed that they help teachers and students, at least when taking articles into consideration although difference in the use of these two types are inconsiderable.

\subsubsection{Types of written corrective feedback}

Explored more deeply, types of feedback can be classified as follows.

Direct and indirect feedback: Ferris (2002, p.19) averred direct feedback as instructors' explicit provision of the correct linguistic form for students (word, morpheme, phrase, rewritten sentence, deleted word(s). This definition is somehow similar to the term "explicit correction" by Lyster and Ranta in 1999. Indirect feedback by contrast occurs when teachers indicate by symbols or signals that an error has been made, leaving student to self-correct them. Ellis (2009) stated that indirect and implicit correction is often done by underlining the errors or using cursors to show the omissions or by placing a cross in the margin. Findings from previous studies on effectiveness of these two types show remarkable contrast. Ferris and Roberts ' study in 2001 concluded that there were no difference between direct and indirect CF, as opposed to Lalande's claim in1982 that indirect feedback performed better. 
Metalinguistic CF: Ellis (2009) defined metalinguistic $\mathrm{CF}$ as some form of explicit comment about the nature of error in two ways: uses of error code like abbreviated labels and use of metalinguistic explanation of the errors. Interestingly, different findings have been claimed. Lalande found that students who were provided with error code outperformed slightly in comparison with those given direct feedback. Ferris and Roberts in 2001 also voiced that error code assisted students to self-edit their writing. Nonetheless, effectiveness on student's accuracy in using articles between direct feedback and metalinguistic feedback were evidenced in study by Sheen (2007).

Focused and unfocused CF: The former differs from the latter in that focused feedback refers to correcting just one type of error, while unfocused $\mathrm{CF}$ refers to correcting all or the most of the errors. Pointed out by Ellis (2009), both two types have advantages. For example, Ellis (2009) claims that "focused CF may prove more effective as the learner is able to examine multiple corrections of a single error and thus obtain the rich evidence they need to both understand why what they wrote was erroneous and to acquire the correct form" (p.102). Karimi and Fotovatnia (2010) carried out a study whose findings revealed that focused and unfocused $\mathrm{CF}$ can make an equal contribution to grammatical accuracy. Similarly, Rouhi and Samiei in 2010 came up with no statistically significant difference among focused and unfocused groups. Meanwhile, another study by Farrokhi (2011) proved focused CF outperforms unfocused in building grammatical accuracy for learners.

Given contradictory conclusion of effects of different feedback types in both theoretical and practical aspects, it is hardly easy to come to an end which feedback strategy is useful for all ill-formed sentences in student writings and there exists paucity of arguments inquiring the preferences of teachers and students. The study is therefore an attempt to explore this practice on contextual teaching at SFL, TNU.

\section{Methodology}

\subsection{Statement of Problem}

In conjunction with the burning debates over the use of WCF, the study of WCF is conducted to investigate the practicality of using WCF by teachers and students in English Division, SFL, TNU to date.
Frankly speaking, neither clear valid findings nor personal truthful sharing related to the use has been made undiscovered. They may be, if any, spoken sharing amongst teachers as topics of their casual meetings. As a teacher in charge of writing subjects and starting from my own personal experience, I feel a strong need to learn about the fact and make some revolutionary and well-grounded choices to the teaching and learning English as a second language in my context.

\subsection{Purpose and Research Questions}

On the basis of the above rationale behind for the study, the following research questions have been addressed:

a. What attitudes prevail among the circle of teachers at School of Foreign Languages, Thai Nguyen University?

b. Which type(s) of corrective feedback is the most frequently used by the teachers?

c. How do the students perceive and evaluate the use of WCF by their teachers?

d. Which difficulties in the application of WCF do the teachers face?

\subsection{Participants}

The study was conducted at School of Foreign Languages, Thai Nguyen University, Vietnam with 40 students and 12 teachers in essay-writing classes participating the study, all of whom are Vietnamese. For the student group, the student population was almost 150 , and the number of 40 is regarded as a good sample for the whole population. Demographic information collected from the students indicates that the majority of them are female aged between 20 and 22. Student participants are the seniors who learnt how to write academically argumentative essays as a preparation for their future high-stake tests like IELTS or TOEFL for 15 weeks at the second semester of their academic year, challenged with a total of thrice practicing writing this type of essay. For each time they are asked to write essays of 3 drafts: first, mid, and final drafts and then peer check either in-class or at home to design a portfolio.

Also present in this study were 12 teachers in charge of teaching writing essay in particular and written subjects in general. They are almost in the age range of 25 to 35 and holders of M.A degrees and their English proficiency is almost equal to $\mathrm{C}$. 
Possessing and experiencing different teaching styles, their activities are various but identical in that they use peer feedback as a component in their formative assessment to their student. In general, teacher's help of preliminary correction on the first and mid drafts is often more facilitative than evaluative. They only give grade as an evaluation of the writing on the final draft. Peer reviewing and teacher feedback were conducted during in-class hours and even at home. The teacher provides feedback on both content, morphological, semantic, and grammar/ syntactic features, which all belong to the classification of feedback by Ellis (2009).

\subsection{Instruments}

The instrument devised to collect data were two different questionnaires with one version in Vietnamese for student groups and the other in English for the teacher who filled in the online survey separately at different place and time. Answers in each questionnaire all cater for the research questions. Data collection was carried out in the $14^{\text {th }}$ and $15^{\text {th }}$ weeks of the semester. Both questionnaires are included in the Appendices. To develop the questionnaire items, the author has consulted theoretical suggestions by Dorney and other questionnaires in formerly done studies. However, the content was modified with different items to match the purpose of the study. Both questionnaires were composed of demographic information, attitudinal questions, behavioral questions and learners and teaches' expectation. For attitudinal items, the response is a 5-scale answer from strongly agree to strongly disagree. However, the response for behavioural questions was expressed from "always" to "never". Participants can answer open questions by writing their own ideas or closed on by answering MCQ, Yes/No, etc. Before officially used to elicit data, questionnaires had been pilot-tested with a small group in the class of hers to ensure that the questionnaire was not ambiguous and of validity. As a result, some changes in the wording and sequencing of some items was made. Then, the author calculated the questionnaire reliability using Cronbach's alpha for each revised questionnaire until the final one had an acceptable reliability $(>=0.6)$.

Students and teachers who participated in the study were also invited to take a follow-up short interview to help the author triangulate her research's findings. Special attention were taken to ensure the interviewees answer the questions carefully and cooperatively but with ease.

\subsection{Procedures}

The participants were selected in the style of nonsampling. After revising and applying some related theories of statistics on how to choose a sample that can represent the whole population, the author decided that above 40 would be the reliable number of participants. The student participants have to write at least three essays of argumentation for the whole semester under the guidance of their teachers who then corrected the essays directly or indirectly. The researcher wrote a questionnaire and gave it to the student participants. She also presented them a reward of VND 10,000 as a way to motivate them to join in the study. The aim of the questionnaire is to figure out students and teachers' behaviors towards the use of written corrective feedback, their difficulty and expectations or preferences in essay class.

\section{Results}

This part analyzes the data collected from the research instrument, at the same time makes accordingly conclusive statement and compared the findings with those of previous studies.

\subsection{Prevalent attitudes toward written corrective feedback}

This part presents the answer to the first question that "What attitudes prevail among the circle of teachers and students in School of Foreign Languages, Thai Nguyen University?" The data elicited from the respondents are demonstrated charts found in the Appendices.

Two thirds of teachers responding to the questionnaire agreed strongly with the usefulness of making student rewrite their essays while only one of them did not think that way. This indicate that students are advised to rewrite their essay using feedbacks to produce a best essay for themselves. Furthermore, the majority of them find written feedback a useful and helpful activity as shown by Figures 2 and 8 . However, when it comes to opinions on types and amount of feedback they should have, teachers have dissimilar and divergent ideas. Three in ten teachers have the idea that teacher should mark and correct all the errors made by students meanwhile the remaining believe they should not. The outnumbered hesitant group seem to depend on the class-size, types of errors and preference over 
student's peer-checking. (Figure 3). Teachers mostly favour to select errors that are typical and serious or detrimental to the communication of ideas, as given by Figures 4, 5 and 6. In order to promote the practice of WCF for students' essays, many teachers gave different forms of compliments, as indicated in Figure 9. These forms can be arranged from the most commonly used to least one as follows: the good points to be highlighted, suggestion of sharing excellent writings, writing positive and praising comments, and asking students making a portfolio of essays.

\subsection{Frequent written corrective feedback used by teachers}

As discussed in the previous parts, feedback types can be classified by different approaches; however, this paper will employ the one suggested by Ellis (2009, p8) as the theoretical framework for the analysis of data, which aims at answering the research question: "Which type(s) of corrective feedback is the most frequently used by the teachers?"

In general, teachers pay attention to different types of errors, the most commented of which go to sentence structure, followed by the way the ideas are organized, linked and developed (organization, cohesion and task achievement), each at over ninety percent. Lexical features are also given feedback while errors related to functional words like articles and pronouns are of the least concern. Interestingly,it can be seen from Figure 11 that half of the teachers stay neutral on whether or not to give direct feedback, and more of them shared that they hardly directly provide the corrections for the students. The findings completely match following questions in Figures 12 and 13 , which tell that teacher frequently underline or circle the errors or put a mark in the margin, leaving student opportunity to correct errors on their own. This reveals that teachers expect or suppose their students should realize and correct errors themselves and in fact, they give their students a checklist (error code) for students'self-check (Figure 14), suggest using dictionaries, or peer-checking (Figures 15 and 16). The study's survey also looked into if teachers corrected their students' writing with any computeraided tools. The findings from Fig. 17 turn out that given the average class-size, students' writings are still mainly given feedback manually, with about two thirds of teachers saying that they hardly ever use technology for their work. Their manual correction is composed of both oral and written explanations for students (Fig. 17)

Possibly, due to the overloaded amount of students' writing paper for correction, the vast majority of teachers (around eight out of ten) picked up selectively and randomly some to check and correct (Fig. 19) and most of them then often collected common errors on board/ or slides for the whole class. (Fig. 20). The findings indicate that the teaching writing essay at SFL is still traditional and not technology-intesive to reduce the cumbersome for teachers.

Students in essay writing groups received not only the feedback from their teachers but also that from their peers. This is why two thirds of teachers adopted the class policies that require students to peer-check. In doing so, teacher often observe their students' exchange and discussion of ideas in order to make their written pieces of essay better.

\subsection{Difficulties in the application of $W C F$}

As far as obstacles of providing WCF are concerned, teachers share more similar responses. First, the percentage of teacher who always found giving feedback time-consuming is more than 80 percent, as four times high as those finding at a lesser extent.

The feeling of being overwhelmed hindered teachers quite often, experienced by nearly 60 percent, almost as twice as the figure of those interested in giving WCF. The remaining percentage is made up by the number of neutral respondents. As opposed to many expectations, teachers find checking symbols are more difficult for their students to understand (one third versus one fourth of them, respectively). Another obvious difficulty for teachers is the matter of available time for checking errors. Given the current teaching context, as many as nine out of ten teachers find there is an acute short of time for them to deal with all errors made by students. (Fig. 24). Teachers seem also challenged at different degrees when having to group students on the basis of their needs for corrective feedback with the majority claiming the frequency of "always, often, and sometimes". As somewhat mentioned and discussed earlier, the use of IT literacy in providing feedback represents another obstacle for teachers; however, it is fortunate that the percentage of those at ease and without ease using IT is the same. Also, the triangulated interviews revealed 
that the IT equipment is acute and not sufficiently well-equipped to facilitate teaching. The last group of difficulties appear to come from students themselves. A significant percentage of teachers find at a high frequency that their students is not good at dictionary skills for lexical choices (Fig.26) or unable to understand their teachers' comments (Fig. 27). Students are found to be rather frequently lack of interest in the feedback from teachers although a considerable percentage of over 40 percent reveals that they are excited at it. Unfortunately, many of the students, though, do not have a good cooperation with their teachers and overlook suggestions by teachers.

\subsection{Students' uptake and evaluation on the use of WCF by their teachers}

The massive majority of students appear to be in favour of the usefulness and necessities of essays for their academic and life purposes. Many of them strongly believe that essay practices also better their writing ability and confidence and share that they often crystalize their thoughts into such pieces of compositions as essays, diaries or short stories. When questioned about their general assessment of corrective feedback activities in classroom, almost 90 percent of them find them necessary, and impressively none of them think they are not. (Fig. 28). It is important to notice that teachers seem to have awareness of their students' wants. Almost 65 percent of students expressed that their teachers gave corrective feedback on both their outlined and completed writings. Then the final drafts were the second ranked pieces of essays to be often given feedback, with responses from over twenty percent of students. Apart from teacher' feedback, students were guided to do peer-check in a way that they were given instructions on how to check errors in a writing. Peerchecking can be done in either of any previous draft prior to the final one or all of them. However, the first and final drafts are given more attention. The input turned out that they spend most of their efforts on pointing out errors of ill-formed sentences (grammar errors) with just under six of ten students doing so, and they then care for organization, lexical choices and content at quite an identical level.

As regards students' appreciation of teacher's written corrective feedback, students mostly think they are of great sense and that they learn a lot from them as evidenced by Fig. 29. However, the rate of their evaluation on peer-check is much less positive, with seven in ten students prefer peer-feedback and three in ten would rather not apply it. This finding can stem from the guidance and checklist teachers should have provided students with and it is possible that teachers should have an insight into how peerfeedback or comments can be measured and recorded. Another finding for peer-check is that students prefer as many people as possible to provide them feedbacks. It is clear that they generally would like teachers to apply this form and they can exchange ideas and learn from others and grow more confident as writers. Moreover, as high as two thirds of students suggest teachers that written corrective feedback should be implemented in subsequent academic terms for writing essays courses.

\section{Conclusions and implications}

The question of "to give or not to give feedback" when tailored and customized at School of Foreign Languages, Thai Nguyen University has been clarified. The results revealed that teachers share an agreement and support to the use of written corrective feedback in their teaching although their preferred focuses vary greatly. Therefore, there is a great need for a checklist that are agreed and approved by all teachers to be applied in teaching essays. On the other hand, student groups also generally take interest into teachers' feedback. Therefore, teacher should extend the scale of use for other writing classrooms at other levels. Teachers should apply peer checking for students as long as they feel a peer pressure to ensure the quality of the checking. The present findings would tend to suggest another avenues for teachers interested in written corrective feedback: How peer feedback among students can be measured and assessed; how teacher students be more motivated when given corrective feedback and better at writing essays.

\section{REFERENCES}

1. Alimohammadi, B. \& Nejadansari, D. (2014), Written Corrective Feedback: Focused and Unfocused, Theory and Practice in Language Studies, Volume 4, 581-587;

2. Azizi, M., Behjat, F., \& Sorahi. M.A. (2014). Effect of Metalinguistic Teacher Corrective Feedback on Writing Performance of Iranian EFL Learners. International Journal of Language and Linguistics. Special Issue: Innovations in Foreign Language 
Teaching, 2, 54-63. Retrieved October 25, 2015, from http://article.sciencepublishinggroup.com/pdf/10.11648. j.ijll.s.2014020601.18.pdf;

3. Bitchener, J. (2008). Evidence in support of written corrective feedback. Journal of Second Language Writing, 17, 102-118;

4. Cohen, A.D., \& Cavalcanti M. C. (1990). Feedback on compositions: Teacher and student verbal reports. In Hamouda, A. (2011) A Study of Students and Teachers' Preferences and Attitudes towards Correction of Classroom Written Errors in Saudi EFL Context. Vol 4 (3). ELT;

5. Cumming, A. (2001). Learning to write in a second language: Two decades of research. International Journal of English Studies, Vol 1 (2), 1-23;

6. Ducken, D. (2014). Written Corrective Feedback in the L2 Writing Classroom. EWU Master's Thesis Collection, Paper 221, 1-78;

7. Ellis, R. (2009). A typology of written corrective feedback types. ELT Journal Volume 63, 97-107;

8. Farrokhi, F., \& Sattarpour, S. (2011). The effects of Focused and Unfocused Written Corrective Feedback on Grammatical Accuracy of Iranian EFL Learners. Theory and Practice in Language Studies, 1(12), 1797-1803;

9. Ferris and Roberts (2001) Ferris D.R. and Roberts, B. (2001). Error feedback in L2 writing classes: How explicit does it need to be? Journal of Second Language Writing, 10, 161-184;

10. Ferris, D. R. (2002). Treatmentof error in second language student writing. Ann Arbor: University of Michigan Press;

11. Ferris, D. R. (2007). Preparing teachers to respond to student writing. Journal of Second Language Writing, 16, 165-193;

12. Hansen, J.G. \& Liu, J. (2005). Guiding principles for effective peer response. ELT Journal, Vol 59, 31-38;

13. Hyland, F., \& Hyland, K. (2001). Sugaring the pill: Praise and criticism in written feedback. Journal of Second Language Writing, 10, 185-212;

14. Karim, K. (2013). The effects of direct and indirect written corrective feedback (CF) on English-as-asecondlanguage (ESL) students' revision accuracy and writing skills. MA, University of Victoria, 1-191;

15. Lalande, J. F. (1982). Reducing composition errors: an experiment. In Karim, K. (2013). The effects of direct and indirect written corrective feedback (CF) on English-as-a-secondlanguage (ESL) students' revision accuracy and writing skills. MA, University of Victoria, 1-191;
16. Lee, I. (2003). L2 writing teachers' perspectives, practices and problems regarding error feedback. Assessing Writing, 8, 216- 237;

17. Lee, I. (2005). Error correction in the L2 writing classroom: What do students think? TESL Canada Journal, 22 (2);

18. Lyster, R. \& Ranta, L. (1997). Corrective Feedback and Learner Uptake. Negotiation of Form in Communicative Classrooms. SSLA, 19, 37-66;

19. Morris, G. (2014). Using Peer Review to Improve Student Writing. Univesity of Michigan. Retrieved on October 17, 2015, from http://www.lsa.umich.edu/UMICH/sweetland/Home/F or\%20Students/Writing\%20References\%20and\%20R esources/Using\%20Peer\%20Review\%20to\%20Impro ve $\% 20$ Student $\% 20$ Writing.pdf;

20. Myles, J. (2002). Second Language Writing and Research: The Writing Process and Error Analysis in Student Texts. TESL - EJ. Vol. 6. Retrieved on October 15, 2015, from http://www.cc.kyotosu.ac.jp/information/tesl-ej/ej22/a1.html;

21. Norouzian, R. \& Farahani, A.A.K. (2012). Written Error Feedback from Perception: A Feedback on Feedback. Journal of Language Teaching and Research. Vol. 3, p. 11-22;

22. Russell, J. \& Spada, N. (2006). The effectiveness of corrective feedback for the acquisition of L2 grammar: A meta-analysis of the research, Chapter 4;

23. Salimi, A. \& Ahmadpour, M. (2015). The Effect of Direct vs. Indirect Written Corrective Feedback on L2 Learners Written Accuracy in EFL Context. International Journal of English Language and Literature Studies, 4(1), 10-19, Retrieved on October $22, \quad 2015, \quad$ fromhttp://www.aessweb.com/pdffiles/ijells-2015-4(1)-10-19.pdf;

24. Sanavi, V. R. \& Nemati, M. (2014). The Effect of Six Different Corrective Feedback Strategies on Iranian English Language Learners ' IELTS Writing. SAGE Journal, Retrieved on October 20, 2015, from http://sgo.sagepub.com/content/4/2/2158244014538271

Sheen, Y. (2007). The effect of focused written corrective feedback and language aptitude on ESL learners' acquisition of articles. TESOL Quarterly, 41, 255-83;

25. Truscott, J. (1996). The case against grammar correction in L2 writing. In D. Ducken (2014). Written Corrective Feedback in the L2 Writing Classroom. EWU Master's Thesis Collection, Paper 221, 1-78;

26. Zamel, V. (1985). Responding to student writing. TESOL Quarterly, 19, 79-102. 